\title{
Notch ligand Delta-like 1 as a novel molecular target in childhood neuroblastoma
}

\author{
P. Bettinsoli*, G. Ferrari-Toninelli, S. A. Bonini, C. Prandelli and M. Memo
}

\begin{abstract}
Background: Neuroblastoma is the most common extracranial solid malignancy in childhood, responsible for 15\% of all pediatric cancer deaths. It is an heterogeneous disease that does not always respond to classical therapy; so the identification of new and specific molecular targets to improve existing therapy is needed. We have previously demonstrated the involvement of the Notch pathway in the onset and progression of neuroblastoma. In this study we further investigated the role of Notch signaling and identified Delta-like 1 (DLL 1) as a novel molecular target in neuroblastoma cells with a high degree of MYCN amplification, which is a major oncogenic driver in neuroblastoma. The possibility to act on DLL1 expression levels by using microRNAs (miRNAs) was assessed.
\end{abstract}

Methods: DLL1 mRNA and protein expression levels were measured in three different neuroblastoma cell lines using quantitative real-time PCR and Western Blot analysis, respectively. Activation of the Notch pathway as a result of increased levels of DLL1 was analyzed by Immunofluorescence and Western Blot methods. In silico tools revealed the possibility to act on DLL1 expression levels with miRNAs, in particular with the miRNA-34 family. Neuroblastoma cells were transfected with miRNA-34 family members, and the effect of miRNAs transfection on DLL1 mRNA expression levels, on cell differentiation, proliferation and apoptosis was measured.

Results: In this study, the DLL1 ligand was identified as the Notch pathway component highly expressed in neuroblastoma cells with MYCN amplification. In silico analysis demonstrated that DLL1 is one of the targets of miRNA-34 family members that maps on chromosome regions that are frequently deregulated or deleted in neuroblastoma. We studied the possibility to use miRNAs to target DLL1. Among all miRNA-34 family members, miRNA-34b is able to significantly downregulate DLL1 mRNA expression levels, to arrest cell proliferation and to induce neuronal differentiation in malignant neuroblastoma cells.

Conclusions: Targeted therapies have emerged as new strategies for cancer treatment. This study identified the Notch ligand DLL1 as a novel and attractive molecular target in childhood neuroblastoma and its results could help to devise a targeted therapy using miRNAs.

Keywords: Neuroblastoma, Notch pathway, Delta-like 1, miRNAs, Molecular target

\footnotetext{
* Correspondence: paola.bettinsoli@unibs.it

Department of Molecular and Translational Medicine, University of Brescia

Medical School, Viale Europa, 11 Brescia, Italy
}

(c) The Author(s). 2017 Open Access This article is distributed under the terms of the Creative Commons Attribution 4.0 International License (http://creativecommons.org/licenses/by/4.0/), which permits unrestricted use, distribution, and reproduction in any medium, provided you give appropriate credit to the original author(s) and the source, provide a link to the Creative Commons license, and indicate if changes were made. The Creative Commons Public Domain Dedication waiver (http://creativecommons.org/publicdomain/zero/1.0/) applies to the data made available in this article, unless otherwise stated. 


\section{Background}

Neuroblastoma is an embryonic tumor of the sympathetic nervous system which arises during fetal or early postnatal life from sympathetic cells derived from the neural crest [1]. It is the most common solid extracranial malignancy of childhood and is responsible for $15 \%$ of all pediatric cancer deaths. Neuroblastoma is an extremely heterogeneous disease; tumors can spontaneously regress or differentiate, even without therapy, or display a very aggressive malignant phenotype that is poorly responsive to current intensive multimodal therapy [2-4]. Despite high-dose chemotherapy, surgery and radiotherapy, in half of cases the tumor has a survival rate of less than 40\% [5]. Unsatisfactory response to classical therapies may be attributable to the clinical, biological and histological heterogeneity of "neuroblastomas". Thus, the identification of novel selective target molecules is needed, to improve existing therapies and to develop new, specific, innovative and less aggressive therapeutic approaches [6, 7]. Our previous study recognized one of the molecular pathways involved in neuroblastoma to be a component of the Notch signaling pathway [8]. The Notch pathway is an highly conserved cell signaling system that regulates cell fate decisions during embryogenesis, modulates the differentiated state of mature cells and is also one of the main factors in the regulation of "cancer stem cells" [9, 10]. Several studies have demonstrated the importance of Notch signaling in the tumor microenvironment and its involvement in many aspects of the disease: the onset of tumor, angiogenesis, the ability to invade tissues and metastasize [11-16]. Depending on organ and tissue type, Notch signaling can function either as a promoter to support tumor development or as a suppressor to inhibit tumor growth. Deregulated expression of Notch proteins, ligands, and targets has been described in a multitude of solid tumors including renal, lung, pancreatic, hepatocellular and gastric carcinoma, melanoma and medulloblastoma [17]. Notch activation is responsible for increased growth and proliferation of neuroblastoma cell lines. On the contrary, Notch pathway downregulation by gamma-secretase inhibitors causes proliferation arrest and cell differentiation [8]. In this study we wanted to investigate in detail the role of Notch signaling in neuroblastoma and we analyzed the role of Notch pathway components, three receptors (Notch1, Notch 2 and Notch 3) and five canonical ligands (Delta-like 1, Delta-like 2, Delta-like 4, Jagged 1 and Jagged 2), in three neuroblastoma cell lines. We identified DLL1 as the Notch pathway component highly expressed in IMR-32 cells, a cell line with a high degree of $M Y C N$ amplification. About $20 \%$ of neuroblastoma cases are characterized by $M Y C N$ gene amplification, which has been correlated with tumor progression and is routinely used as a clinical biomarker for treatment stratification $[18,19]$. The correlation between Delta-like Notch ligand expression and development of other tumors has already been characterized. Overexpression of DLL1 was identified in choriocarcinoma [20] and hepatocellular carcinoma [21], while Delta-like 4 (DLL4) expression was correlated to tumor initiation and progression of glioblastoma [22], poor prognosis in pancreatic cancer [23] and colon cancer [24]. We evaluated the possibility to act on the expression of DLL1 by using miRNAs. During the past decades the involvement of miRNAs in several human diseases, including cancer, has been intensively investigated. miRNAs are a class of small, 19-22 nucleotides, non-coding endogenous single-stranded RNAs that act as posttranscriptional regulators of specific messenger transcripts (mRNAs), resulting in targeted degradation or suppression of gene expression [25, 26]. More than 4469 miRNAs have been identified in Homo sapiens, of which 1881 are precursors and 2588 are mature (miRBase, Release 21: June 2014) and most of these miRNAs are highly conserved across species. It has been reported that miRNAs are able to control more than $60 \%$ of human protein-coding genes $[27,28]$. In physiologic conditions miRNAs are key regulators involved in biological processes such as development, proliferation, differentiation, migration, neuroplasticity, survival and death. miRNAs dysregulation contributes to the onset of different pathologies such as heart disease, diabetes, mental disorders and cancer. Because $50 \%$ of miRNAs genes are located at genomic sites associated with cancer-specific chromosomal rearrangements and because of the proximity of their genes to chromosomal breakpoints, miRNAs have been associated with tumorigenesis. In some cancer types miRNAs appear to be upregulated and are thus thought to act as oncogenes, while they are downregulated in other types of cancers, which may be indicative of a tumor suppressor function. miRNAs expression is dynamic: many miRNAs are deregulated in early stages of tumor development and upregulated during cancer progression, which underscores the importance of the cellular microenvironment [29]. miRNAs can be used as biomarkers to discriminate cancer from normal tissue, to diagnose the onset of a tumor, to indicate the degree of dissemination and to monitor the response to drug treatments, or as therapeutic targets in the design of a real "miRNA-based therapy" [28]. In silico analyses suggest that DLL1 is one of the targets of the miRNA-34 family; miRNA-34a maps to the distal region of chromosome $1 \mathrm{p}$ which is commonly deregulated or deleted in neuroblastoma (www.mirbase.org). miRNA-34a can antagonize many different oncogenic processes by regulating genes that function in various cellular pathways. The anti-oncogenic activity of miRNA-34a has been demonstrated in cancer cells of the lung [30,31], pancreas [32, 33], brain [34, 35], ovary [36], prostate [37] as well as in lymphoma and leukemia [38]. miRNA-34a inhibits the propagation properties of tumor-initiating cells derived 
from medulloblastoma [39] and it is downregulated in glioblastoma tissues, where its overexpression could suppress cell proliferation and induce apoptosis, indicating that this miRNA may act as tumor suppressor also in this type of tumor [40]. miRNA-34b is significantly downregulated in prostate cancer and its reconstitution induced anti-proliferative and antimigratory effects and suppressed tumor growth in an in vivo xenograft nude mouse model, suggesting the tumor suppressor function of this miRNA [41]. Also, in breast cancer, miRNA-34b acts as an oncosuppressor regulating the complex estrogenic pathway, which could lead to the development of new therapeutic strategies [42]. The miRNA-34 family was the most extensively studied miRNAs in neuroblastoma and Welch and colleagues were the first to report that miRNA-34a was generally expressed at lower levels in unfavorable primary neuroblastomas and cell lines compared to normal adrenal tissue. miRNA-34a induced cell cycle arrest, apoptosis, and significantly reduced tumor growth in an in vivo orthotopic murine model of neuroblastoma [35]. Our data indicate that, within the miRNA-34 family, miRNA-34b induced significant downregulation of DLL1 mRNA expression levels, cell differentiation and arrested cell proliferation in IMR-32 neuroblastoma cells. This study identified Notch ligand DLL1 as a new and specific molecular target in childhood neuroblastoma, suggesting that miRNAs could be a novel therapeutic tool to develop an effective strategy to attack "DLL1 positive" neuroblastoma.

\section{Methods}

\section{Cell lines}

The human SH-SY5Y neuroblastoma cell line (DSMZ) was cultured in a 1:1 mixture of Ham's F12 nutrient and Dulbecco's modified Eagle's medium (Sigma-Aldrich) supplemented with $10 \%$ fetal bovine serum (FBS, SigmaAldrich), $2 \mathrm{mM} \mathrm{L}$-glutamine, $50 \mathrm{mg} / \mathrm{mL}$ penicillin, and $100 \mathrm{mg} / \mathrm{mL}$ streptomycin (Sigma-Aldrich). The IMR-32 neuroblastoma cell line (DSMZ) and the KELLY neuroblastoma cell line (Sigma-Aldrich) were grown in RPMI medium (Sigma-Aldrich) supplemented with 10\% FBS (Sigma-Aldrich), $2 \mathrm{mM} \mathrm{L-glutamine,} 50 \mathrm{mg} / \mathrm{mL}$ penicillin, $100 \mathrm{mg} / \mathrm{mL}$ streptomycin (Sigma-Aldrich), and $1 \times$ MEM nonessential amino acid solution (Sigma-Aldrich). All the cell lines were grown at $37{ }^{\circ} \mathrm{C}$ in a $95 \%$ air $-5 \%$ $\mathrm{CO} 2$ humidified incubator.

\section{siRNAs and miRNAs transient transfection}

siRNA probes targeted to the DLL1 ligand were purchased from Dharmacon (Dharmacon, Inc., Lafayette, CO, USA). Human-specific DLL1 interference was performed using an Accell SMARTpool siRNA mixture containing a mixture of four siRNAs targeting the DLL1 gene. A non-targeting Accell siRNA pool was used as a control in siRNA transfection experiments. IMR-32 neuroblastoma cells were transfected with Accell siRNAs, using Hi-perfect transfection reagent (Qiagen) in culture medium with $3 \%$ normal serum 1 day after seeding. Cells were maintained in culture for three more days after transfection with $20 \mathrm{nM}$ siRNA. IMR-32 neuroblastoma cells were transfected with different miRNA-34 (miRNA-34a, miRNA-34b, miRNA-34c, Qiagen) and miRNA-210 (Qiagen), as internal control, using Hi-perfect transfection reagent (Qiagen) in culture medium with $3 \%$ normal serum 1 day after seeding. Cells were maintained in culture for three more days after transfection with $10 \mathrm{nM}$ miRNAs.

\section{Quantitative real-time PCR}

Quantitative real-time PCR (RT-qPCR) was executed as described below. The total RNA was isolated from $\mathrm{SH}$ SY5Y, KELLY and IMR-32 neuroblastoma cells using the RNeasy kit (Qiagen) and digested with the RNase-Free DNase set (Qiagen), according to the manufacturer's protocol. One microgram of total RNA was transcribed into complementary DNA (cDNA) using murine leukemia virus reverse transcriptase (Promega Italia) and oligo(dT)15-18 as a primer (final volume: $50 \mu \mathrm{l}$ ). The oligonucleotide sequences of the primers used are as follows: N-Myc forward primer 5'-CGA CCA CAAGGC CCT CAG TA-3', reverse primer $5^{\prime}$-CAG CCTTGG TGT TGG AGG AG-3'; DLL1 forward primer 5' ACGAATGCTGCTGCTGAAGAGGAGGGA-3, reverse primer 5 '-AACTGTCAATAGTGCAACGGCGAC-3';D LL3 forward primer 5'-AGCGTCACACAATCACGA AG-3', reverse primer 5' ${ }^{\prime}$-TGGTATGAACCAGAGCTACCG-3'; DLL4 forward primer 5'-AACTGCCCTT CAATTTCACCT-3', reverse primer $5^{\prime}$-GCTGGTTT GCTCATCCAATAA-3'; Jagged 1 forward primer 5'AGACATCGATGAATGCGTCA-3', reverse primer 5' CCACAGACGTTGGAGGAAAT-3'; Jagged 2 forward primer 5'-TGGCACTCGCTGTATGAAAG-3', reverse primer 5'-AGGGCCACATCAATAACCAG-3'; GAPDH forward primer $5^{\prime}$-GAG TCA ACG GAT TTG GTC GT-3', reverse primer 5'-TTG ATT TTG GAG GGA TCT CG-3'. Amplification and detection were performed with the iCYCLER iQ Real Time PCR Detection System (BioRad Italia, Milan, Italy); the fluorescence signal was generated by SYBR Green I. Samples were run in triplicate in a $25 \mu \mathrm{l}$ reaction mix containing $12.5 \mu \mathrm{l} 2 \times$ SYBR Green Master Mix (BioRad Italy), $12.5 \mathrm{pmol}$ of each forward and reverse primer and $2 \mu$ l of diluted cDNA. The PCR program was initiated by $10 \mathrm{~min}$ at $95{ }^{\circ} \mathrm{C}$ followed by 40 cycles, each for $15 \mathrm{~s}$ at $95^{\circ} \mathrm{C}$ and $1 \mathrm{~min}$ at $60^{\circ} \mathrm{C}$. Gene expression levels were normalized to GAPDH expression and data are presented as the fold change in target gene expression in drug-treated cells normalized to the internal control gene (GAPDH) and relative to untreated cells. Results were estimated as $\mathrm{Ct}$ 
values; the $\mathrm{Ct}$ was calculated as the mean of the $\mathrm{Ct}$ for the target gene minus the mean of the $\mathrm{Ct}$ for the internal control gene. The $\mathrm{Ct}$ represented the mean difference between the $\mathrm{Ct}$ of untreated cells minus the $\mathrm{Ct}$ of treated cells. The $\mathrm{N}$-fold differential expression in the target gene of drug-treated cells compared with untreated cells was expressed as $2^{-\Delta \Delta C t}$. Data analysis and graphics were performed using Graph Pad Prism 5 software and the results of experiments were run in triplicate.

\section{Western blot analysis}

Total cell lysates were prepared by scraping the cells in lysis buffer (50 mM Tris pH 7.6, $150 \mathrm{mM} \mathrm{NaCl}, 2 \mathrm{mM}$ EDTA, $0.5 \%$ NP40 with a cocktail of protease inhibitors). For Western blot analysis, $15 \mu \mathrm{g}$ of total proteins were electrophoresed onto 10\% SDS-PAGE and transferred to nitrocellulose paper. Filters were incubated with anti-Notch 1 antibody (Sigma-Aldrich; 1:1000), anti-Neuronal Nuclei antibody (Millipore; 1:1000), anti- $\beta$ III tubulin (Promega; 1:1000) and anti-Glyceraldehyde-3-phosphate dehydrogenase antibody (Millipore; 1:500) as loading control. After washing, membranes were incubated with HRP-conjugated antimouse and antirabbit secondary antibody (Dako; 1:1500) and a chemiluminescence blotting substrate kit (Amersham Biosciences) was used for immunodetection. Evaluation of immunoreactivity was performed on immunoblots by densitometric analysis using the Quantity One analysis software (BioRad Laboratories $\mathrm{GmbH}$ ).

\section{Immunofluorescence and morphometric analysis}

Immunofluorescence and morphometric analyses were executed as described below. SH-SY5Y cells were plated with a density of $75 \times 10^{3}$ /well in a 24 wells plate, grown on a glass coverslip (coated with poly-l-lysine, SigmaAldrich); IMR-32 cells were plated with a density of $50 \times$ $10^{3} /$ well and grown on a glass coverslip coated with collagen IV (BD Bioscience). Cells were fixed in ice-cold methanol (Sigma-Aldrich), then washed and incubated in Phosphate Buffered Saline (PBS, Sigma-Aldrich) containing $1 \%$ of Bovine Serum Albumin (BSA, SigmaAldrich) and $0.2 \%$ Triton $\mathrm{X} 100$ overnight at $4{ }^{\circ} \mathrm{C}$ with a polyclonal anti- $\beta$ III tubulin (Sigma-Aldrich, 1:600), monoclonal anti-Notch 1 (Sigma-Aldrich, 1:1000). After rinses, cells were incubated with Alexa Fluor ${ }^{\circ} 488$ (Life Technologies, 1:400) anti rabbit secondary antibody and $\mathrm{CY}^{\mathrm{sm}} 3$-conjugated anti-mouse secondary antibody (Jackson Immunoresearch Laboratories INC.,1:500) in PBS for $1 \mathrm{~h}$ at room temperature. For morphological evaluation, slices were mounted and examined by a ZEISS LSM 510 META confocal laser-scanning microscope (Carl Zeiss, Germany). Images were processed using LSM5 image examiner software (Zeiss). The percentage of morphologically differentiated cells was determined by analyzing at least 10 fields for each treatment; cells with neurites $\geq 50 \mu \mathrm{m}$ in length were considered as differentiated.

\section{Flow Cytometry for analysis of cell cycle and apoptosis} For cell cycle analysis, cells were harvested at the completion of the miRNAs treatments and washed with phosphate-buffered saline (PBS; pH 7.4) before being fixed with $70 \%$ ethanol on the wheel for $15 \mathrm{~min}$ at $4{ }^{\circ} \mathrm{C}$. Subsequently, the cells were centrifuged at $4500 \mathrm{rpm}$ for 5 min at $4{ }^{\circ} \mathrm{C}$, washed with phosphate-buffered saline and were resuspended in $600 \mu \mathrm{l}$ of $0,1 \%$ sodium citrate (Sigma-Aldrich), $50 \mu \mathrm{g} / \mathrm{ml}$ of propidium iodide (PI, Sigma-Aldrich) and $10 \mu \mathrm{g} / \mathrm{ml}$ of Ribonuclease A (SigmaAldrich) for staining cellular DNA. The cellular DNA content was then analyzed using a MACS Quant Flow Cytometer (Miltenyi Biotec). Data analysis was carried out using FlowJo software. For the apoptosis analysis, after treatment with miRNAs $10 \mathrm{nM}$, cells were washed with PBS and stained with Annexin V-FITC and PI using the Apoptosis Detection Kit (Bender Medsystems) according to the manufacturer's protocol. Annexin-positive cells were counted using a MACS Quant Flow Cytometer (Miltenyi Biotec) within $1 \mathrm{~h}$ after staining. Data analysis was carried out using FlowJo software.

\section{Statistical analysis}

Statistical analyses were performed by one-way analysis of variance followed by Bonferroni's multiple comparison test as post hoc analysis. Data are presented as the mean \pm Standard Error Mean (S.E.M). Probabilities $<0.05$ and $<0.001$ were considered a significant difference.

\section{Results}

DLL1 is the notch pathway component highly expressed in MYCN amplified neuroblastoma cells

At first, the role of Notch pathway components was investigated in neuroblastoma cell lines with different $M Y C N$ gene amplification degree, which is related to aggressiveness and malignant phenotype. RT-qPCR was performed in three cell lines: SH-SY5Y cell line with low degree of MYCN amplification, IMR-32 and KELLY with high degree of $M Y C N$ amplification [43].The N-Myc mRNA expression levels were established by RT-qPCR, that confirmed a barely detectable $\mathrm{N}$-Myc expression in SH-SY5Y cells and a higher N-Myc expression levels in KELLY and IMR-32 cells (Fig. 1a). The mRNA expression levels of three Notch receptors (Notch 1, Notch 2 and Notch 3) and five Notch ligands (Delta-like 1, Deltalike 3, Delta-like 4, Jagged 1 and Jagged 2) were analyzed by RT-qPCR and we identified DLL1 as the Notch pathway component highly expressed in IMR-32 cells (Fig. 1b). Receptors were also analyzed but uniformity was not found among the three cell lines (Additional file 1). 


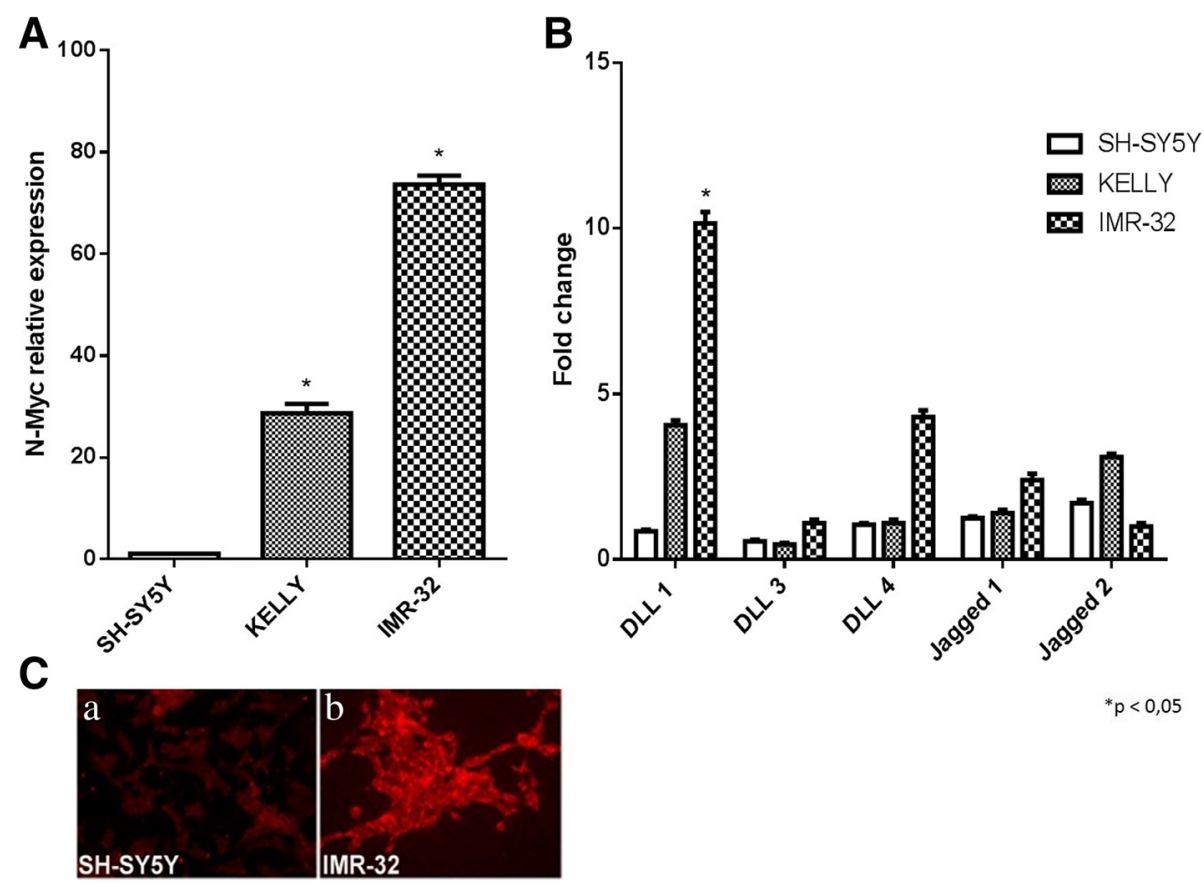

Fig. 1 Analysis of Notch ligands expression in neuroblastoma cells with different MYCN gene amplification. a RT-qPCR analysis of N-Myc mRNA expression levels in SH-SY5Y, KELLY and IMR-32 neuroblastoma cell lines. b RT-qPCR analysis of the five mammalian Notch ligands in SH-SY5Y, KELLY and IMR-32 neuroblastoma cell lines. c Immunofluorescence analysis of DLL1 protein expression in SH-SY5Y and IMR-32 neuroblastoma cells. ${ }^{*} p<0.05$ vs SH-SY5Y cell line

DLL1 protein expression was also analyzed by immunofluorescence that confirmed the high ligand levels in IMR-32 cells compared with SH-SY5Y cell line (Fig. 1c).

High DLL1 ligand expression levels are associated with notch pathway activation in IMR-32 neuroblastoma cells To verify if DLL1 increased levels leads to an effective Notch pathway activation, the expression of NICD protein (Notch Intracellular Domain, Notch 1 activated form) in SH-SY5Y and IMR-32 neuroblastoma cells was analyzed. SH-SY5Y and IMR-32 cells were cultured for $48 \mathrm{~h}$ in complete medium and then analyzed by immunofluorescence. A stronger Notch activation was found in IMR-32 cells compared to SH-SY5Y (Fig. 2a). This result was confirmed by Western blot and densitometric analysis, showing a significant increase of NICD protein level in IMR-32 cell line (Fig. 2b, c).

\section{Selective DLL1 downregulation by siRNA induces neuroblastoma cell differentiation}

Since DLL1 was identified as the Notch pathway component most expressed in IMR-32 neuroblastoma cells, and since DLL1 increased levels lead to an effective Notch pathway activation, we investigated $D L L 1$ molecular targeting by observing the effects of $D L L 1$ gene silencing via RNA interference technique in neuroblastoma cells. First, the efficacy of various siRNAs at different concentrations (5 nM, $10 \mathrm{nM}, 20 \mathrm{nM}$ and $40 \mathrm{nM}$ ) was assessed in terms of their ability to induce significant DLL1 downregulation. We identified siRNA 5 at the concentration of $20 \mathrm{nM}$ as the most capable to significantly downregulate DLL1 mRNA expression levels; siRNA - (non-targeting siRNA pool) $20 \mathrm{nM}$ was used as scrambled negative control (Additional file 2). To study the effect of siRNA on neuroblastoma cell differentiation, IMR-32 cells were transfected with siRNA 5 $20 \mathrm{nM}$ and cells were analyzed by immunofluorescence. Confocal microscopy analysis showed that DLL1 downregulation by siRNA 5 induced neuronal differentiation, characterized by changes in cell morphology such as longer neurites, as obtained with 13-cis retinoic acid (Fig. 3a). Retinoic acid was used as a positive control because it is a potent cellular differentiation agent able to induce growth inhibition and cell differentiation in normal and cancer cell types. Retinoic acid is currently used in neuroblastoma treatment, in association with standard therapeutic protocols, as neoadjuvant agent [44]. It is interesting and significant that DLL1 downregulation induced a cell differentiation comparable to the effect obtained with 13-cis retinoic acid. A quantitative analysis of morphological differentiation confirmed that DLL1 downregulation induced a statistically significant increase in the number of differentiated cells (Fig. 3b). 

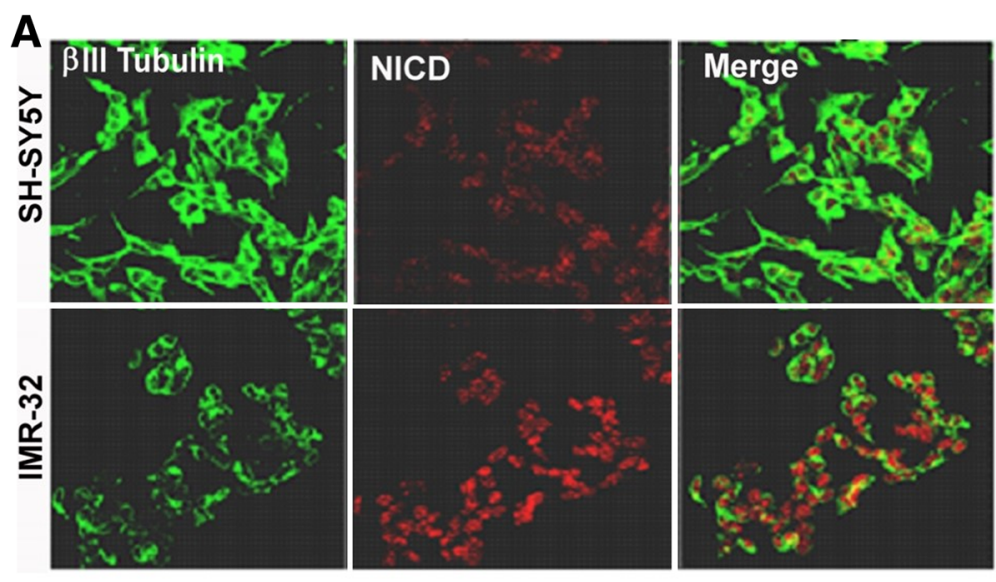

B

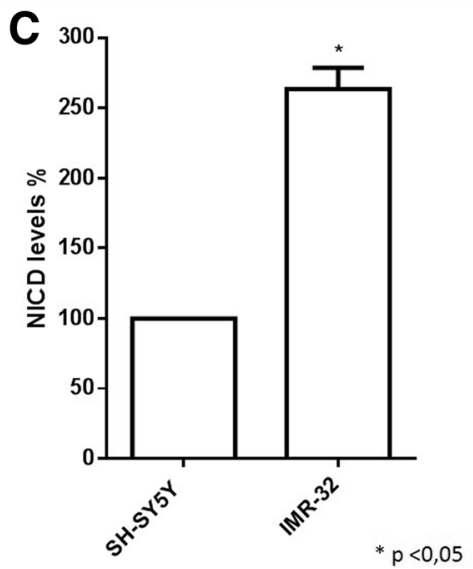

Fig. 2 Analysis of Notch pathway activation in neuroblastoma cells with different MYCN gene amplification. SH-SY5Y and IMR-32 cells were chosen as the two cell lines with the lowest and the highest N-Myc mRNA expression. a Confocal analysis of NICD expression levels in SH-SY5Y and IMR-32 cells. $\beta$ III tubulin antibody (green) was used as neuron marker; NICD antibody (red) showed a typical nuclear localization, indicative of Notch activation. $\mathbf{b}$ Western blot analysis of NICD protein expression in SH-SY5Y and IMR-32 cells. c Densitometric analysis of NICD expression levels in SH-SY5Y and IMR-32 cells using Quantity One analysis software. ${ }^{*} p<0.05$ vs SH-SY5Y cell line

\section{DLL1 is downregulated in IMR-32 neuroblastoma cells treated with miRNA-34b}

In silico analysis using Target Scan 6.2 (Released June 2012) predict that the DLL1 is a potential target of miRNA-34 family members. IMR-32 neuroblastoma cells were transfected with miRNA-34 family members (miRNA-34a, miRNA-34b, miRNA-34c) and miRNA210 as internal control. miRNA-210 was chosen as internal control because in silico analysis has shown that it is not correlated to Notch signaling. miRNA-210 expression is related to diseases such as lung adenocarcinoma [45] and cerebral ischemia [46]. Cells were transfected with the miRNAs at three different concentrations (5, 10 and $20 \mathrm{nM}$ ) and RT-qPCR analysis of DLL1 mRNA expression levels showed that in cells treated with miRNA-34b, at the concentration of $10 \mathrm{nM}$, it was observed a significant downregulation of DLL1 mRNA expression levels (Fig. 4). This data suggest an important role of miRNA-34b in DLL1 downregulation. At concentrations of $5 \mathrm{nM}$ and $20 \mathrm{nM}$, no significant differences between control and treated cells were found. We observed that the $5 \mathrm{nM}$ concentration had no effects, while $20 \mathrm{nM}$ concentration was toxic for cells which showed clear signs of cell suffering, and the analysis on cell extracts of RNA revealed no differences in expression levels.

\section{miRNA-34b induces differentiation in IMR-32 neuroblast- oma cells}

The possible morphological changes after miRNAs transfection on IMR-32 neuroblastoma cells were evaluated. Analysis by confocal microscopy showed that miRNA-34b transfection induced significant cellular differentiation, characterized by longer neurites (Fig. 5a), increasing the number of differentiated cells compared to control (Fig. 5b). Morphological analysis was accompanied by biochemical patterns resembling the neuronal phenotype. We therefore measured the levels of neuronal specific markers including Neuronal Nuclei protein $(\mathrm{Neu} N)$ and $\beta$ III tubulin by Western blot. Protein expression levels of Neu $\mathrm{N}$ were strongly increased after 

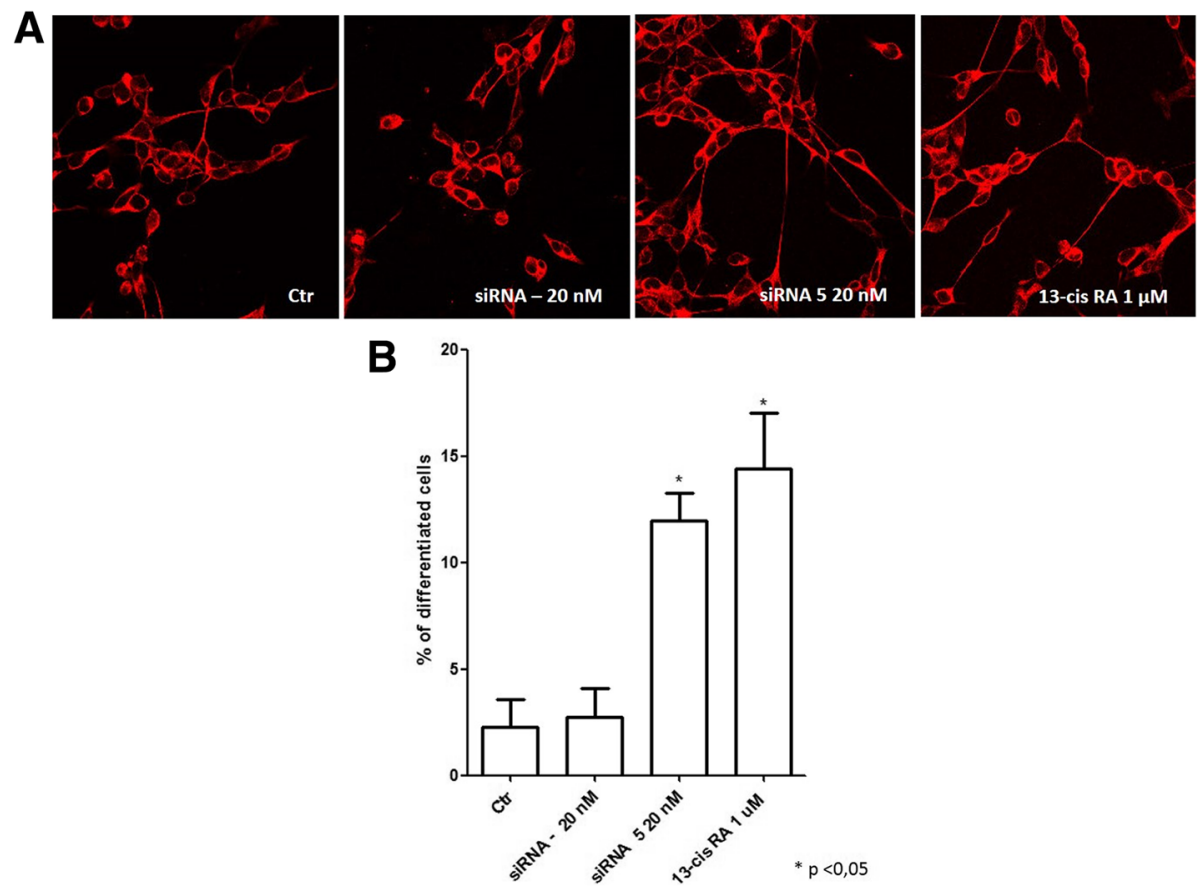

Fig. 3 Analysis of siRNA DLL1 and 13-cis retinoic acid treated IMR-32 neuroblastoma cell line. a Confocal analysis of siRNA DLL1 and 13-cis retinoic acid in IMR-32 neuroblastoma cells after 3 days of transfection. $\beta$ III tubulin antibody was used as neuron marker. b Morphometric analysis of cell differentiation induced by siRNA DLL1 and 13-cis retinoic acid. Neuronal differentiation was evaluated by measuring neurite length. The percentage of differentiated cells was calculated, considered as cells with neurites $\geq 50 \mu \mathrm{M}$ in length in IMR-32 cells. ${ }^{*} p<0.05$ vs control

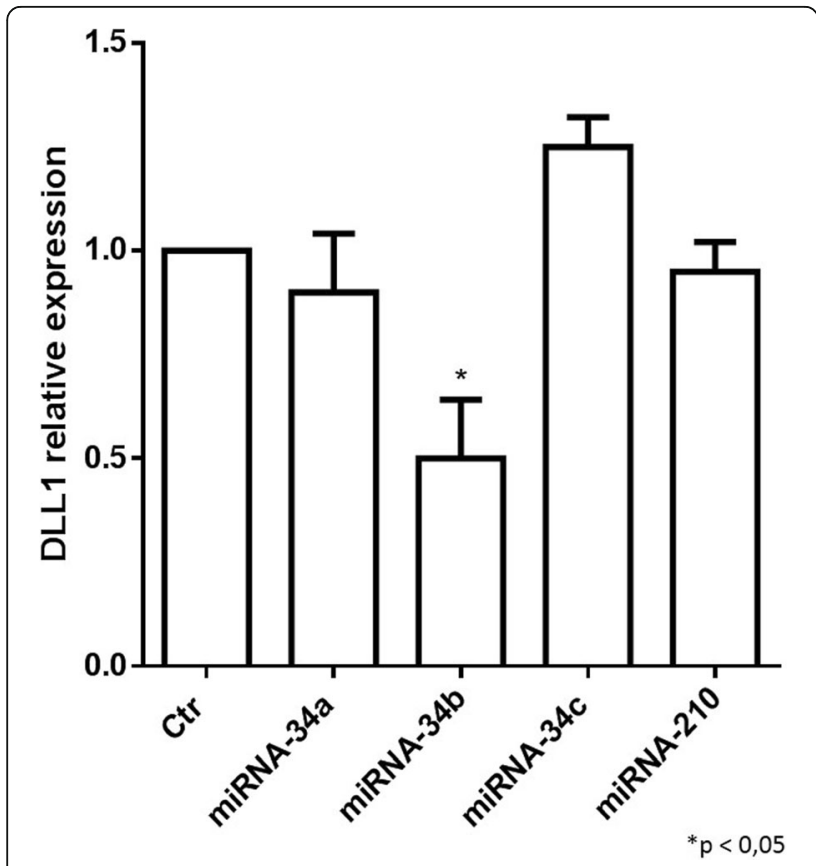

Fig. 4 RT-qPCR analysis of DLL1 mRNA expression levels in IMR-32 neuroblastoma cell line. Analysis of DLL1 mRNA expression levels after Authors' contribution3 days of transfection with all miRNA-34 family members and with miRNA-210. ${ }^{*} p<0.05$ vs control
miRNA-34b treatment (Fig. 6a); the protein expression levels of $\beta$ III tubulin were also increased even if the data was not statistically significant (Fig. 6b). These results suggest that miRNA-34b may function as a cell fate regulator, which modulates early cell differentiation in IMR-32 neuroblastoma cells.

miRNA-34 family members induce cell proliferation arrest in IMR-32 neuroblastoma cells

The ability of miRNAs to arrest cell proliferation was assessed by cell cycle analysis. miRNA-34b induced an increase in the number of cells in G0/G1 phase (* $p<0.001)$ and a decrease in the number of cells in $S$ phase $\left.{ }^{(* * * *} p<0.001\right)$ of the cell cycle, compared to respective control. Other members of miRNA-34 family have such effects. The data indicate that the treatment with all miRNA-34 family members blocked the cells in the G0/G1 phase, decreasing the number of proliferating tumoral cells (Fig. 7). The effect of miRNA-34b is peculiar and specific for differentiation pathway and not for cell proliferation arrest.

miRNA-34 family members do not induce apoptosis in IMR-32 neuroblastoma cells

Finally a possible apoptotic effect of miRNAs on IMR-32 neuroblastoma cells was analyzed. Cytofluorimetric analysis, by Annexin V-positive cells, revealed that members of the miRNA-34 family do not induce apoptosis in the 


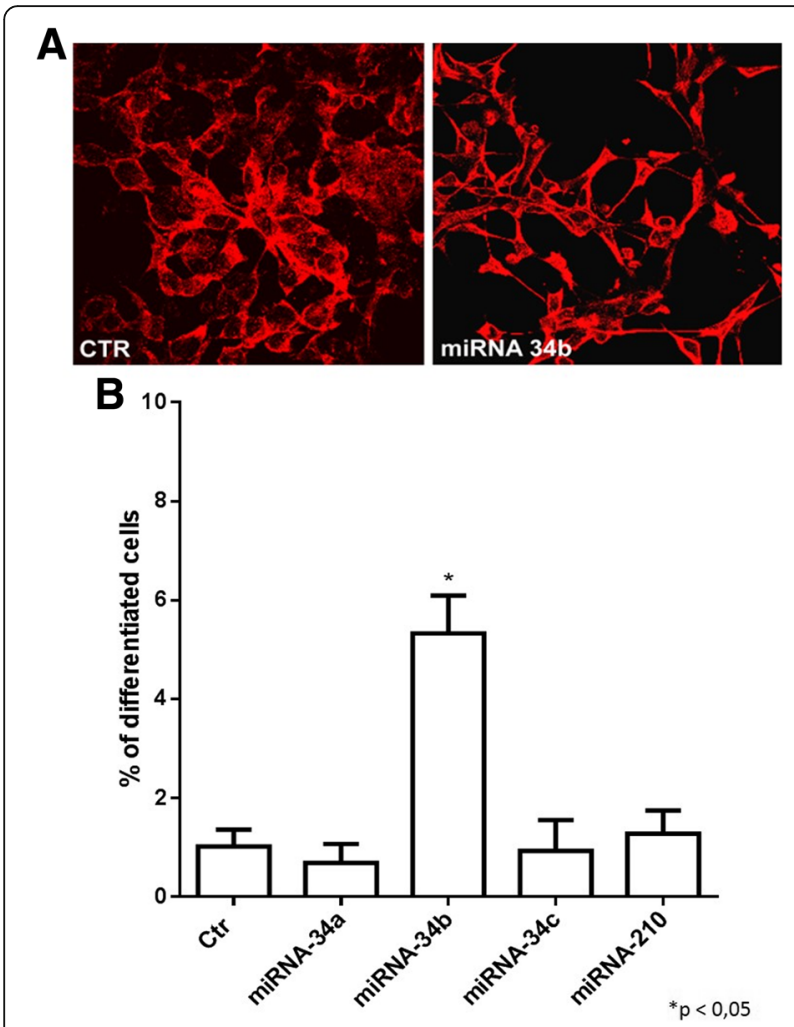

Fig. 5 Analysis of miRNA-34b transfection in IMR-32 neuroblastoma cells line. a Confocal analysis of miRNA-34b transfection in IMR-32 neuroblastoma cells after 3 days of transfection. $\beta$ III tubulin antibody was used as neuron marker. $\mathbf{b}$ Morphometric analysis of cell differentiation induced by miRNAs transfection. IMR-32 neuroblastoma cells underwent 3 days of transfection and then neuronal differentiation was evaluated by measuring neurite length. The percentage of differentiated cells was calculated, considered as cells with neurites $\geq 50 \mu \mathrm{M}$ in length in IMR-32 cells. ${ }^{*} p<0.05$ vs control

IMR-32 neuroblastoma cell line (Fig. 8a, b). These data suggest that miRNAs treatments drive the cells in G0/ G1 phase towards a differentiation profile instead to cell death.

\section{Discussion}

In the present study Notch ligand DLL1 emerged as a novel molecular target in childhood neuroblastoma and miRNAs could be an innovative tool to attack "DLL1 positive" tumors. The DLL1 ligand was observed to be the most expressed Notch pathway component in MYCN amplified neuroblastoma cells and its downregulation, with miRNAs, induced differentiation and an arrest of cell proliferation. Recently, the focus of cancer research has been the identification of new molecular targets which will permit to act with more specific and effective drugs, thereby paving the path towards innovative therapeutic strategies. The involvement of the Notch pathway in tumors, including neuroblastoma, has previously been described; our group has demonstrated that

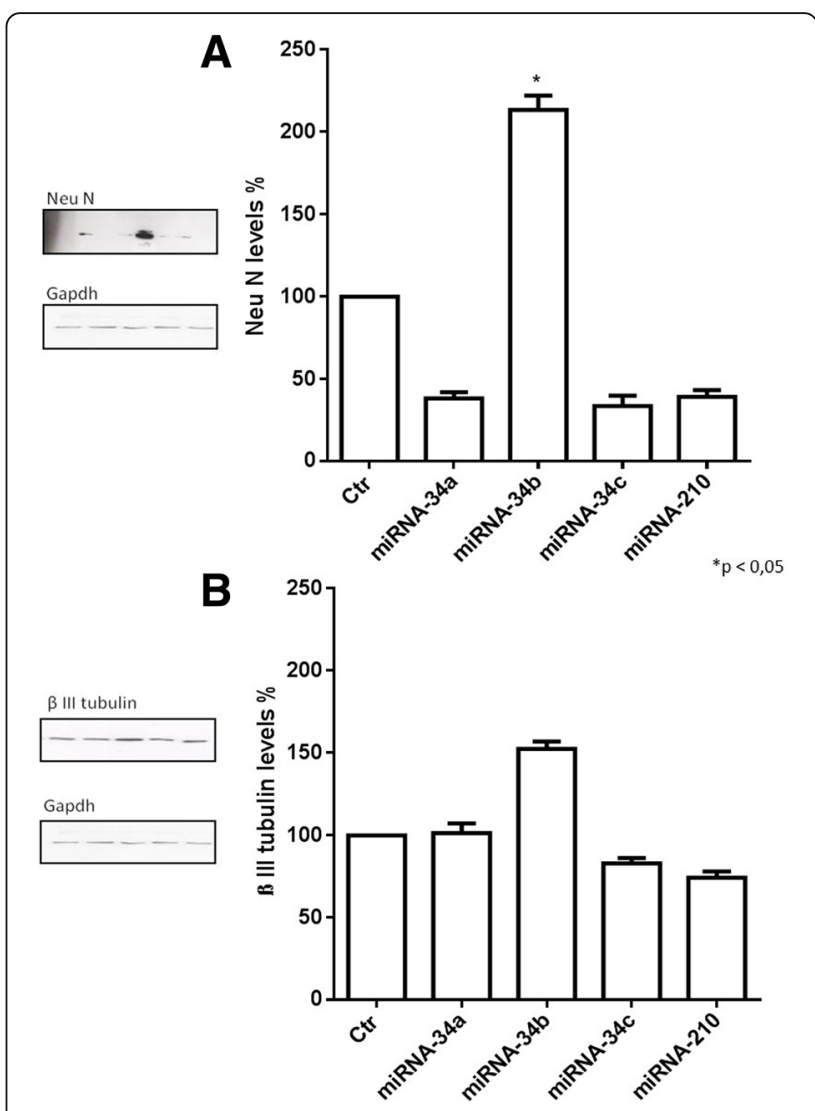

Fig. 6 Western Blot analysis of IMR-32 neuroblastoma cell line. Western Blot analysis of Neu N (a) and $\beta$ III tubulin (b) protein expression levels after 3 days of miRNAs transfection. ${ }^{*} p<0.05$ vs control

Notch activation is responsible for growth and proliferation of neuroblastoma cells, while its inhibition causes proliferation arrest and cell differentiation [8]. DLL1 is a transmembrane ligand of the Notch signaling pathway that is also overexpressed in other types of tumor, such as choriocarcinoma [20] and medulloblastoma [39], indicating a probable strong involvement of this Notch pathway component in the onset of such tumors. Furthermore, DLL1 is not only implicated in tumorigenesis, it is also involved in sympathetic ganglia development where the protein maintains the proliferation state of embryonal cells $[47,48]$. In the present study DLL1 was found to be highly expressed in IMR-32 cells, a cell line with a high degree of $M Y C N$ gene amplification. The $M Y C N$ proto-oncogene plays an important role in neuroblastoma development; about $30 \%-40 \%$ of advanced stage tumors exhibit $M Y C N$ amplification, which has been correlated to rapid tumor progression, drug resistance and poor outcome $[49,50]$. Thus, these data probably suggest that DLL1 expression is dependent on the degree of $M Y C N$ gene amplification, although further work is needed to demonstrate this. Zhao and colleagues had previously demonstrated that Delta-like 3 


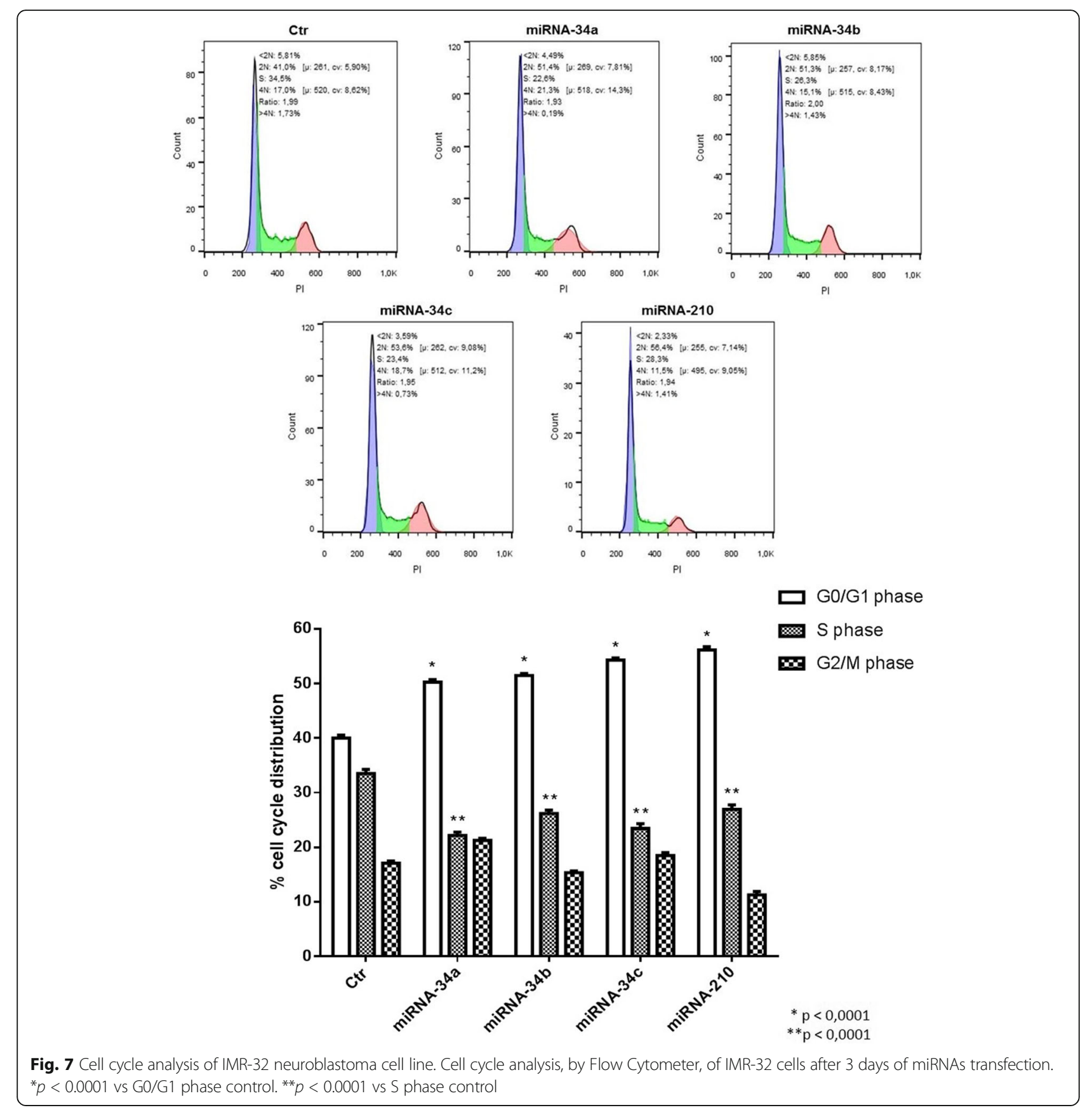

(DLL3) is a direct transcriptional target of N-Myc, identifying a new "N-Myc-DLL3" pathway as a mediator of neural development in brain [51]. Recently, miRNAs have emerged as a new promising therapy in many different diseases, including cancers, thanks to their ability to modulate selective molecules at post-transcriptional level [52, 53]. miRNAs act as fine regulators of cancer development, functioning as oncogenes or tumor suppressor, and they can be used to form the new "miRNAbased therapy" for cancer [54, 55]. In silico analysis showed that DLL1 ligand is one of the targets of
miRNA-34 family, which is known for its potential tumor suppressing role in several cancers including neuroblastoma, glioblastoma, and medulloblastoma. In neuroblastoma tissues and cell lines, members of the miRNA-34 family are expressed at very low levels and their ectopic expression induce cell cycle arrest, apoptosis, and a reduction of tumor growth in vivo [56]. The data suggest a role for miRNA-34a as a potential tumor suppressor in neuroblastoma [35], and for miRNA-34b as an oncosuppressor in in vitro prostate cancer models and breast cancer $[41,42]$. In this study miRNA-34b was 

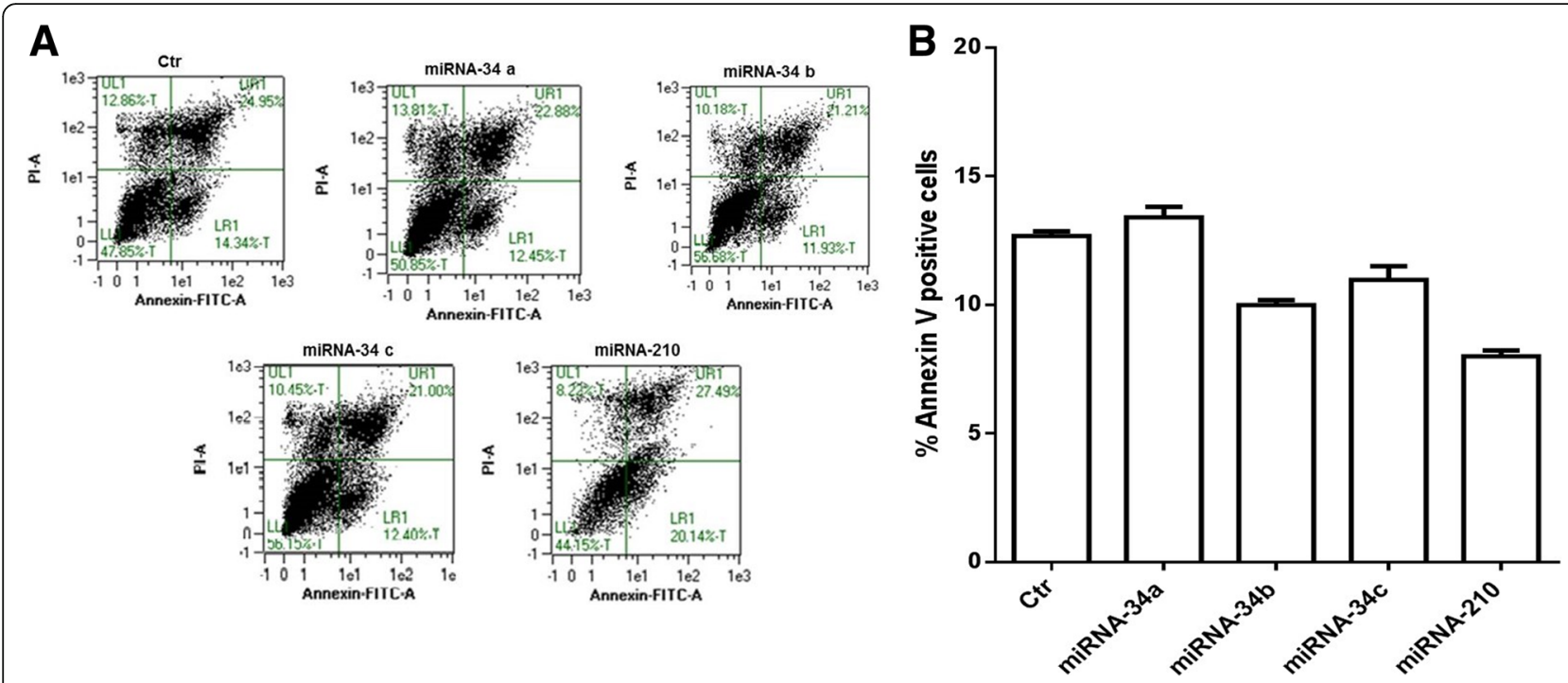

Fig. 8 Apoptosis analysis of IMR-32 neuroblastoma cell line. a Annexin V/PI double staining and flow cytometry assays. X-axis indicates the number of Annexin V-FITC-stained cells. Y-axis indicates the number of Pl-stained cells. b Determination of apoptosis percentages based on the accumulation of Annexin V-positive cells

able to significantly downregulate DLL1 ligand and to induce neuronal differentiation, much more than other components of the miRNA-34 family. This divergence may be due to the fact that the sequences of miRNA-34a and miRNA-34b differ for few nucleotides and the different actions of miRNAs probably depend on the tumor microenvironment, cell lines used, as well as the choice of in vivo tumoral model. One of the mechanisms of action of miRNAs is the induction of apoptosis, through the activation of a caspase-dependent apoptotic pathway, and the inhibition of proliferation [36]. The results obtained in IMR-32 neuroblastoma cell line demonstrate that members of the miRNA-34 family are able to induce a significant arrest of tumor cell proliferation but not to induce apoptosis. Probably cells blocked in G0/ G1 phase move towards a path of cell differentiation and not apoptotic death. Whether miRNAs induce apoptosis presumably depends on the cellular context and on the expression levels of the miRNA-34 target proteins involved in the regulation of apoptosis.

\section{Conclusions}

This study was conducted in order to identify the Notch pathway components highly involved in neuroblastoma genesis and progression. DLL1 emerged to be the ligand highly expressed in cell lines with high $M Y C N$ gene amplification, indicative of increased degree of malignancy. Downregulation of the ligand inhibited cell proliferation and induced differentiation, suggesting a prooncogenic role for DLL1. The ligand DLL1 was also shown to be a potential target of miRNA-34b, opening the possibility to use miRNAs-based therapy. This idea could be supported by the observation that miRNAs treated cells also showed proliferation arrest and neurite elongation. In conclusion, the data collected point to DLL1 Notch ligand as a new and attractive molecular target in childhood neuroblastoma, and we propose miRNAs as new potential therapy to act on high DLL1 expression. There is strong evidence in the literature supporting the idea that miRNAs could be a new, potentially more effective and specific therapeutic tools, compared with current medical strategies. This study also contributes to the knowledge concerning the role of the Notch pathway in neuroblastoma, shedding light on mechanisms and molecules involved in neuroblastoma pathogenesis.

\section{Additional files}

\section{Additional file 1: Analysis of Notch receptors expression in} neuroblastoma cells with different MYCN gene amplification. RT-qPCR analysis of the three mammalian Notch receptors (Notch 1, Notch 2, and Notch 3) in SH-SY5Y, KELLY and IMR-32 neuroblastoma cell lines. ${ }^{*} p<0$, 05 vs SH-SY5Y cell line. (JPEG 216 kb)

Additional file 2: Analysis of the efficacy of various siRNAs at different concentrations on DLL1 mRNA expression levels in IMR-32 neuroblastoma cells. RT-qPCR analysis of siRNA - (non-targeting siRNA pool), siRNA 2 and siRNA 5 at four different concentrations ( $5 \mathrm{nM}, 10 \mathrm{nM}, 20 \mathrm{nM}, 40 \mathrm{nM})$ in IMR-32 neuroblastoma cell line. ${ }^{*} p<0,05$ vs control. (JPEG $197 \mathrm{~kb}$ )

\section{Abbreviations}

DLL1: Delta-like 1; DLL3: Delta-like 3; DLL4: Delta-like 4; miRNAs: microRNAs

\section{Acknowledgments}

We thank Dr. Kathy-Ann Koralek of the International Affairs of the University of Brescia for English editing. 


\section{Funding}

This work was supported by Research grant from University of Brescia.

\section{Availability of data and materials}

All data generated or analysed during the current study are included in this published article and its supplementary information files.

\section{Authors' contributions}

PB performed experiments and drafted the manuscript. SAB and CP participated in the experiments. GFT and MM designed the study and revised the manuscript. All authors have read and approved the final manuscript.

\section{Competing interests}

The authors declare that they have no competing interest.

\section{Consent for publication}

Not applicable.

\section{Ethics approval and consent to participate} Not applicable.

\section{Publisher's Note}

Springer Nature remains neutral with regard to jurisdictional claims in published maps and institutional affiliations.

\section{Received: 29 February 2016 Accepted: 11 May 2017} Published online: 19 May 2017

\section{References}

1. Ishola AT, Chung DH. Neuroblastoma. Surg Oncol. 2007;16:149-56.

2. Maris JM, Hogarty MD, Bagatell R, Cohn SL. Neuroblastoma. Lancet. 2007; 369:2106-20.

3. Wagner LM, Danks MK. New therapeutic targets for the treatment of highrisk Neuroblastoma. J Cell Biochem. 2009;107:46-57.

4. Davidoff AM. Neuroblastoma. Semin Pediatr Surg. 2012;21:2-14.

5. Garaventa A, Perilongo G. High risk neuroblastoma: a persistent therapeutic challenge. Pediatr Blood Cancer. 2008;51:722-3.

6. Shakeel M, Cheung NV. Neuroblastoma: therapeutic strategies for a clinica enigma. Cancer Treat Rev. 2010;36(4):307-17.

7. Cheung NK, Dyer MA. Neuroblastoma: developmental biology, cancer genomics and immunotherapy. Nat Rev Cancer. 2013:13(6):397-411.

8. Ferrari-Toninelli G, Bonini SA, Uberti D, Buizza L, Bettinsoli P, Poliani PL, et al. Targeting notch pathway induces growth inhibition and differentiation of Neuroblastoma. Neuro-Oncology. 2010;12(12):1231-43.

9. Lathia JD, Mattson MP, Cheng A. Notch: from neural development to neurological disorders. J Neurochem. 2009;107:1471-81.

10. Wang Z, Li Y, Banerjee S, Sarkar FH. Emerging role of notch in stem cells and cancer. Cancer Lett. 2009;279:8-12.

11. Radtke F, Ray K. The Role of Notch in Tumorigenesis: Oncogene or tumour suppressor? Nat Rev Cancer. 2003;3(10):756-67.

12. Leong $K G$, Karsan $A$. Recent insights into the role of notch signalling in tumorigenesis. Blood. 2006;107(6):2223-33.

13. Rehman $A O$, Wang $C Y$. Notch signalling in the regulation of tumor angiogenesis. Trends Cell Bio. 2006;16(6):293-300.

14. Miele L. Notch signalling. Clin Cancer Res. 2006;12(4):1074-9.

15. Bailey JM, Singh PK, Hollingsworth MA. Cancer Metastasis facilited by developmental pathways: sonic hedgehog, notch, and bone morphogenic proteins. J Cell Biochem. 2007;102(4):829-39.

16. Zhang P, Yang Y, Zweidler-McKay PA, Hughes DP. Critical role of notch signalling in osteosarcoma invasion and metastasis. Clin Cancer Res. 2008; 14(10):2962-9.

17. Espinoza L, Miele L. Notch inhibitors for cancer treatment. Pharmacol Ther 2013:139(2):95-110

18. Tang XX, Zhao H, Kung B, Kim DY, Hicks SL, Cohn SL, et al. The MYCN enigma: significance of MYCN expression in Neuroblastoma. Cancer Res. 2006;66(5):2826-33.

19. Maris JM. Recent advances in Neuroblastoma. N Engl J Med. 2010;362(23): 2202-11.
20. Pang RT, Leung CO, Lee CL, Lam KK, Ye TM, Chiu PC, et al. MicroRNA-34a is a tumor suppressor in choriocarcinoma via regulation of Delta-like1. BMC Cancer. 2013;13:25

21. Yu F, Hao X, Zhao H, Ge C, Yao M, Yang S, Li J. Delta-like 1 contributes to cell growth by increasing the interferon-inducible protein 16 expression in hepatocellular carcinoma. Liver Int. 2010;30(5):703-14.

22. Qiu XX, Chen L, Wang CH, Lin ZX, Zhou CF, Liu SY, Wang XF, Chen YP. High delta-like ligand 4 (DLL4) is correlated with peritumoral brain edema and predicts poor prognosis in primary glioblastoma. Medicine. 2014;93(8):e57.

23. Oishi H, Sunamura M, Egawa S, Motoi F, Unno M, Furukawa T, Habib NA Yagita $\mathrm{H}$. Blockade of delta-like ligand 4 signaling inhibits both growth and angiogenesis of pancreatic cancer. Pancreas. 2014;39(6):897-903.

24. Jubb AM, Turley H, Moeller HC, Steers G, Han C, Li JL, Leek R, Tan EY, Singh B, Mortensen NJ, Noguera-Troise I, Pezzella F, Gatter KC, Thurston G, Fox SB, Harris AL. Expression of delta-like ligand 4 (DLL4) and markers of hypoxia in colon cancer. Br J Cancer. 2009;101(10):1749-57.

25. Jansson DM, Lund AH. MicroRNA and cancer. Mol Oncol, 2012:6(6):590-610. Zhi F, Wang R, Wang Q, Xue L, Deng D, Wang S, et al. MicroRNAs in neuroblastoma: small-sized players with a large impact. Neurochem Res 2014; 39(4):613-23

26. Shalaby T, Fiaschetti G, Baumgartner M, Grotzer MA. Significance and therapeutic value of miRNAs in Embryonal neural tumors. Molecules. 2014;19:5821-62.

27. Bader AG. MiR-34a- a microRNA replacement therapy is headed to the clinic. Front Genet. 2012:3:120.

28. Di Leva G, Briskin D, Croce CM. MicroRNA in cancer: new hopes for antineoplastic chemotherapy. Ups J Med Sci. 2012;117(2):202-16.

29. Nana-Sinkam SP, Croce CM. Clinical applications for microRNAs in cancer. Clin Pharmacol Ther. 2012;93(1):98-104.

30. Wiggins JF, Ruffino L, Kelnar K, Omotola M, Patrawala L, Brown D, et al. Development of a lung cancer therapeutic based on the tumor suppressor microRNA-34. Cancer Res. 2010;70(14):5923-30.

31. Lodygin D, Tarasov V, Epanchintsev A, Berking C, Knyazeva T, Körner H, et al. Inactivation of miR-34a by aberrant CpG methylation in multiple types of cancer. Cell Cycle. 2008;7(16):2591-600.

32. Ji Q, Hao X, Zhang M, Tang W, Yang M, Li L, et al. MicroRNA miR-34 inhibits human pancreatic cancer tumor-initiating cells. PLoS One. 2009;4(8):e6816

33. Nalls D, Tang SN, Rodova M, Srivastava RK, Shankar S. Targeting epigenetic regulation of miR-34a for treatment of pancreatic cancer by inhibition of pancreatic cancer stem cells. PLoS One. 2011;6(8):e24099.

34. Chang TC, Wentzel EA, Kent OA, Ramachandran K, Mullendore M, Lee KH, et al. Transactivation of miR-34a by p53 broadly influences gene expression and promotes apoptosis. Mol Cell. 2007;26(5):745-52.

35. Welch C, Chen Y, Stallings RL. MicroRNA-34a functions as a potential tumor suppressor by inducing apoptosis in neuroblastoma cells. Oncogene. 2007; 26(34):5017-22.

36. Corney DC, Hwang Cl, Matoso A, Vogt M, Flesken-Nikitin A, Godwin AK, et al. Frequent downregulation of miR-34 family in human ovarian cancers. Clin Cancer Res. 2010;16(4):1119-28.

37. Liu C, Kelnar K, Liu B, Chen X, Calhoun-Davis T, Li H, et al. The microRNA miR-34a inhibits prostate cancer stem cells and metastasis by directly repressing CD44. Nat Med. 2011;17(2):211-5

38. Craig VJ, Cogliatti SB, Imig J, Renner C, Neuenschwander S, Rehrauer H, et al. Myc-mediated repression of microRNA-34a promotes high-grade transformation of B-cell lymphoma by dysregulation of FoxP1. Blood. 2011; 117(23):6227-36

39. De Antonellis P, Medaglia C, Cusanelli E, Andolfo L, Liguori L, De Vita G, et al. MiR-34a targeting of notch ligand delta-like 1 impairs CD15+/CD133+ tumor-propagating cells and supports neural differentiation in medulloblastoma. PLoS One. 2011;6(9):e24584.

40. Li WB, Ma MW, Dong L, Wang F, Chen LX, Li XR. MicroRNA-34a targets notch1 and inhibits cell proliferation in glioblastoma multiforme. Cancer Biol Ther. 2011;12(6):477-83.

41. Majid S, Dar AA, Saini S, Shahryari V, Arora S, Zaman MS, Chan I, Yamamura S, Tanaka Y, Chiyomaru T, Deng G, Dahiya R. MiRNA-34b inhibits prostate cancer through demethylation, active chromatin modifications, and AKT pathways. Clin Cancer Res. 2013;19(1):73-84

42. Lee YM, Lee JY, Ho CC, Hong OS, Yu SL, Tzeng CR, Yang PC, Chen HW. MiRNA-34b as a tumor suppressor in estrogen-dependent growth of breast cancer cells. Breast Cancer Res. 2011:13(6):R116.

43. Edsjö A, Nilsson H, Vandesompele J, Karlsson J, Pattyn F, Culp LA, Speleman F, Påhlman S. Neuroblastoma cells with overexpressed MYCN retain their capacity to undergo neuronal differentiation. Lab Investig. 2004;84(4):406-17. 
44. Rejnolds PC, Matthay K, Villablanca J, Maurer BJ. Retinoid therapy of highrisk neuroblastoma. Cancer Letter. 2003;197(1-2):185-92.

45. Osugi J, Kimura Y, Owada Y, Inoue T, Watanabe Y, Yamaura T, Fukuhara M, Muto S, Okabe N, Matsumura Y, Hasegawa T, Yonechi A, Hoshino M, Higuchi M, Shio Y, Suzuki H, Gotoh M. Prognostic impact of HypoxiaInducible miRNA-210 in Patients with Lung Adenocarcinoma. J Oncol. 2015; 2015:316745.

46. Zeng L, Liu J, Wang Y, Wang L, Weng S, Tang Y, Zheng C, Cheng Q, Chen S, Yang GY. MicroRNA-210 as a novel blood biomarker in acute cerebral ischemia. Front Biosci. 2011;3:1265-72.

47. Cornell R, Eisen JS. Notch in the pathway: the roles of notch signaling in neural crest development. Cell \& Developmental Biology. 2005;16:663-72.

48. Tsarovina K, Schellenberger J, Schneider C, Rohrer H. Progenitor cell maintenance and neurogenesis in sympathetic ganglia involves notch signaling. Moll Cell Neurosci. 2008;37(1):20-31.

49. Buechner J, Einvik C. N-myc and noncoding RNAs in neuroblastoma. Mol Cancer Res. 2012;10(10):1243-53.

50. Pession A, Tonelli R. The MYCN oncogene as a specific and selective drug target for peripheral and central nervous system tumors. Curr Cancer Drug Targets. 2005;5(4):273-83.

51. Zhao X, D' Arca D, Lim WK, Brahmachary M, Carro MS, Ludwig T, Cardo CC, Guillemot F, Aldape K, Califano A, lavarone A, Lasorella A. The N-Myc-DLL3 cascade is suppressed by the ubiquitin ligase Huwe1 to inhibit proliferation and promote neurogenesis in the developing brain. Dev Cell. 2009;17(2): 210-21.

52. Hoshino L, Matsubara H. MicroRNAs in cancer diagnosis and therapy: from bench to bedside. Surg Today. 2013;43(5):467-78.

53. Das S, Bryan K, Buckley PG, Piskareva O, Bray IM, Foley N, et al. Modulation of neuroblastoma disease pathogenesis by an extensive network of epigenetically regulated microRNAs. Oncogene. 2013;32:2927-36.

54. Chen Y, Stallings RL. Differential patterns of MicroRNA expression in Neuroblastoma are correlated with prognosis, differentiation, and apoptosis. Cancer Res. 2007;67(3):976-83.

55. Ling H, Fabbri M, Calin GA. MicroRNAs and other non-coding RNAs as targets for anticancer drug development. Nat Rev Drug Discov. 2013;12(11): 847-65.

56. Hermeking $\mathrm{H}$. The miR-34 family in cancer and apoptosis. Cell Death Differ. 2010;17(2):193-9.

\section{Submit your next manuscript to BioMed Central and we will help you at every step:}

- We accept pre-submission inquiries

- Our selector tool helps you to find the most relevant journal

- We provide round the clock customer support

- Convenient online submission

- Thorough peer review

- Inclusion in PubMed and all major indexing services

- Maximum visibility for your research

Submit your manuscript at www.biomedcentral.com/submit 